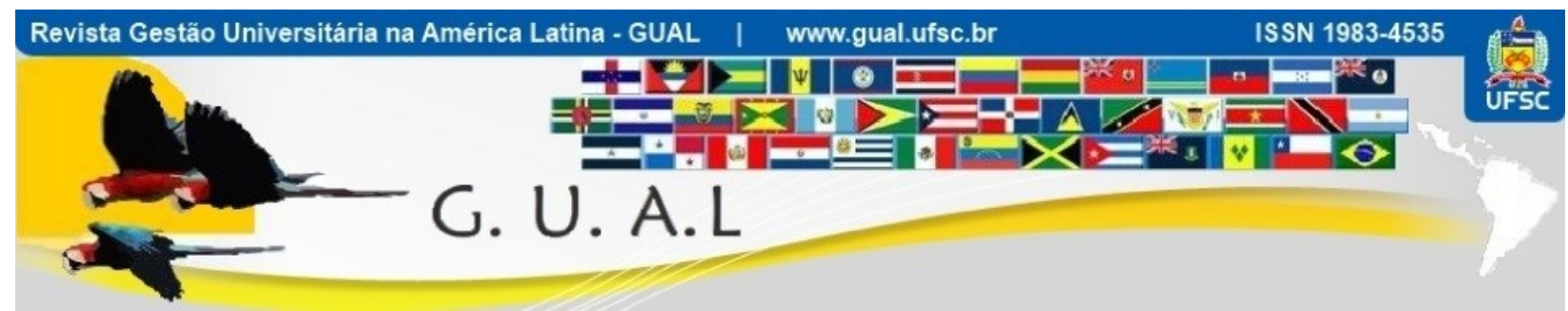

DOI: http://dx.doi.org/10.5007/1983-4535.2013v6n2p79

\title{
INOVAÇÃO DE MARKETING EM INSTITUIÇÕES DE ENSINO SUPERIOR DA SERRA GAÚCHA
}

\section{MARKETING INNOVATION IN HIGHER EDUCATION INSTITUTIONS OF SERRA GAUCHA}

Julio Cesar Ferro de Guimarães, Doutorando

Universidade de Caxias do Sul - UCS juliocfguimaraes@yahoo.com.br

Carina Vedooto Scheneider Coutinho, Mestranda Universidade de Caxias do Sul - UCS carinafsc@hotmail.com

Gabriela Cristina Lain, Mestranda Universidade de Caxias do Sul - UCS gabilain@terra.com.br

Gabriel Sperandio Milan, Doutor Universidade de Caxias do Sul - UCS gabmilan@terra.com.br

Eliana Andréa Severo, Doutorando Universidade de Caxias do Sul - UCS elianasevero2@hotmail.com

Recebido em 02/janeiro/2013

Aprovado em 04/abril/2013

Sistema de Avaliação: Double Blind Review

Esta obra está sob uma Licença Creative Commons Atribuição-Uso. 


\title{
RESUMO
}

Na perspectiva do contexto econômico das organizações, a inovação tem sido alvo de estudo de acadêmicos e empresários, pois apresenta a capacidade de transformar economicamente a situação de uma organização, já que esta é um fator que potencializa a competitividade. As organizações buscam inovações para que através destas melhorem sua performance. Estas inovações ocorrem em diversos setores da economia, como é o caso das Instituições de Ensino Superior (IES). Este setor de serviços cresce na medida em que a população aumenta a capacidade de consumo, o que é evidenciado na demanda por serviços educacionais, pois os profissionais necessitam estar com formação adequada às exigências do mercado. $O$ tema central desta pesquisa é a inovação de marketing em IES, que prestam serviços educacionais de graduação e pós-graduação, na região denominada Corede Serra, a qual conta com 31 municípios, com uma das menores taxas de analfabetismo $(2,66 \%)$ do Brasil. O maior município do Corede Serra é Caxias do Sul, situado na Serra Gaúcha, com 435.564 habitantes, no qual estão sediadas as três IES estudadas. Este trabalho é uma pesquisa qualitativa, descritiva, com escopo de estudo de casos múltiplos, que tem como objetivo identificar e descrever as inovações de marketing, ocorridas nos anos de 2010 e 2011. Os benefícios encontrados no estudo referem-se a melhoria na comunicação com alunos e fornecedores, bem como, a melhoria na qualidade de serviços de suporte, focadas no marketing de relacionamento.

Palavras-chave: Inovação de Marketing. Instituição de Ensino Superior. Educação.

\begin{abstract}
In the perspectives of the economic organizations, innovation has been studied by academics and businessmen, as it has the ability to transform the economic situation of an organization, since this is a factor that enhances competitiveness. Organizations look through these innovations to improve their performance. These innovations occur in diverse industries, such as the Higher Education Institutions (HEI). The service sector grows as the population increases the consumption capacity, as evidenced in the demand for educational services, as the professionals need to be adequately trained to market requirements. The central theme of this research is a marketing innovation in higher education institutions, providing educational services for undergraduate and graduate, in the region called Serra Corede, which has 31 municipalities, with one of the lowest illiteracy rates in Brazil $(2.66 \%)$. The largest city in Serra Corede is Caxias do Sul, witch is located in Serra Gaúcha, with 435,564 inhabitants, where are situated the three studied HEI. This is a qualitative, descriptive, with the scope of multiple case study, which aims to identify and describe the marketing innovations that occurred in the years 2010 and 2011. The benefits found in the study relate to improve communication with students and suppliers, as well as the improvement in the quality of support services, focused on relationship marketing.
\end{abstract}

Keywords: Marketing Innovation. Higher Education Institution. Education. 


\section{INTRODUÇÃO}

No universo econômico das organizações, a inovação tem sido objeto de estudo, pois apresenta a capacidade de transformar economicamente a situação de uma organização (SCHUMPETER, 1934), já que esta é um fator que potencializa a competitividade das organizações (PORTER, 2001; DRUCKER, 2002; KOTLER; KELLER, 2006). Neste sentido atribui-se a inovação o papel de melhorar o desempenho das organizações, seja na otimização da utilização dos recursos ou na conquista de melhores posições no mercado. As organizações de diferentes seguimentos têm buscado, através da inovação, tornar-se mais competitivas diante dos concorrentes (DAMANPOUR, 1991; DRUCKER, 2002).

As empresas buscam inovações para que através destas melhorem sua performance. Estas inovações ocorrem através de mudanças capazes de criar melhorias de desempenho organizacional, podendo incidir sobre os processos, produtos/serviços, marketing ou ainda sobre a gestão organizacional (MANUAL DE OSLO, 2005). A partir do escopo de inovação observa-se que a inovação de marketing é capaz de mudar a percepção do cliente sobre organização, e melhorar significativamente o relacionamento entre fornecedores, empresa e clientes.

Inovação de marketing é a implementação de novas estratégias ou conceitos de marketing que diferem significativamente dos usados previamente pela empresa (PINTEC, 2010). Nesse sentido, o setor de serviços, em especial as Instituições de Ensino Superior (IES), apresenta muitas oportunidades de inovação de marketing, pois a formação dos profissionais demanda constantes atualizações de competências, que são desenvolvidas nos cursos de Graduação e Pós-graduação.

Observa-se que o setor de serviços cresce na medida em que a população aumenta a capacidade de consumo, o que é evidenciado na demanda por serviços educacionais, já que os profissionais necessitam estar com formação adequada às exigências do mercado. O início do século XXI é marcado pela grande busca pela educação, em especial pelo o ensino superior, o qual é impulsionado pela necessidade de qualificação exigida pelo mercado empregador (PALÁCIO; MENESES; PÉREZ, 2002; MICHAEL, 2004). Para diferenciar, as IES promovem inovações, pois a competividade está relacionada diretamente aos métodos e serviços novos prestados aos alunos, os quais contribuem para a melhoria no relacionamento e na qualidade percebida pelo cliente. 
O tema central desta pesquisa é a inovação de marketing em IES, que prestam serviços educacionais de graduação e pós-graduação, na região denominada Corede Serra, a qual conta com 31 municípios, onde reside uma população de 862.305 habitantes, com uma das menores taxas do Brasil de analfabetismo (2,66\%), com expectativa de vida de 74,59 anos e PIB per capta de R\$25.265,00 (FEE, 2011). O maior município do Corede Serra é Caxias do Sul, situado na Serra Gaúcha, com 435.564 habitantes, analfabetismo de 2,36\% e uma renda per capta de R\$28.868,00 (FEE, 2011). No município de Caxias do Sul estão credenciadas junto ao Ministério de Educação 24 IES, sendo 9 Universidades, 14 Faculdades e 1 Instituto Federal de Educação (MEC, 2011). As três IES pesquisadas estão situadas no município de Caxias do Sul.

Este artigo é resultado de uma pesquisa qualitativa, exploratória, com escopo de estudo de casos múltiplos, que tem como objetivo identificar e descrever as inovações de marketing, ocorridas nos anos de 2010 e 2011, em três IES da Serra Gaúcha, sendo duas Faculdades e uma Universidade, em relação às áreas de ensino e serviços de suporte, bem como a comparação entre as IES pesquisadas, além de relatar os benefícios e implicações com as mudanças, evidenciando o impacto sobre o marketing de relacionamento.

\section{REFERENCIAL TEÓRICO}

\subsection{Inovação de Marketing}

Os primeiros estudos sobre inovação focavam basicamente a inovação em um produto dentro de uma fábrica (BROWN; EISENHARDT, 1995). Porém, atualmente, existem estudos (DRUCKER, 1989; SARKAR, 2008; TIDD; BESSANT; PAVITT, 2005) incluindo a área de produtos (ABERNATHY; CLARK, 1985), serviços (GALLOUJ; WEINSTEIN, 1997), processos (FREEMAN, 1997), administrativa (TARRY, 2000; COOPER, 1996) e, inclusive, abordagens multidimensionais (COOPER, 1996).

Neste sentido, a importância do processo de inovação é amplamente reconhecida na academia e nas organizações, e os papeis cada vez mais essenciais a serem desempenhados pelas atividades de serviço em sistemas produtivos, se combinaram para tornar a inovação extremamente relevante no setor de serviços (GALLOUJ; WEINSTEIN, 1997). A forma mais provável de inovar nesta área é através do desenvolvimento de novos serviços ou reformulando os existentes, podendo acontecer através da criação de novos canais de distribuição ou descobrindo novas abordagens de gestão. Estas são essencialmente inovações 
de marketing, pois representam formas de desenvolver novos meios de comercialização a clientes potenciais ou existentes (SLATER; NAVER, 1995).

É oportuno salientar que Schumpeter (1950) foi o primeiro a sugerir que as empresas devem inovar para manter o valor de seus ativos. Bessant et al. (2005) ao discutirem o papel da inovação sugerem que a inovação representa o processo de renovação do núcleo em qualquer organização. O Manual de Oslo é a principal fonte internacional de diretrizes para coleta e utilização de dados sobre atividades inovadoras (OECD, 2005). Este manual define a inovação como sendo a implementação de um produto (bem ou serviço) novo ou significativamente melhorado, ou ainda um processo, ou um novo método de marketing, ou um novo método organizacional nas práticas de negócios, na organização do local de trabalho ou nas relações externas.

Para o Manual de Oslo (2005) toda alteração ou adaptação das estratégias de marketing pode ser considerada uma inovação de marketing. Entretanto, para a inovação de marketing ocorrer é necessário a implementação de novos métodos de marketing, envolvendo melhorias significativas no design do produto ou embalagem, preço, distribuição e promoção (OECD, 2005). Nesse sentido, a inovação de marketing é o que gera a melhoria significativa em alguns dos elementos do marketing (produto, preço, praça e promoção), podendo basearse na diferenciação do produto ou mesmo no preço (HIGGINS, 1995).

Consoante isso, o marketing constitui uma atividade de inovação tecnológica, no momento em que é fundamental para a implantação no mercado de um produto tecnologicamente novo ou aprimorado. O sucesso inovador depende grandemente do grau em que o marketing está integrado com aspectos técnicos do processo de inovação (OECD, 2005). A inovação de marketing não deve ser confundida com inovação de mercado, sendo esta última concentrada em atividades como a entrada em novos mercados (JOHNE; DAVIES, 2000). As inovações de marketing geralmente fornecem correções rápidas e soluções inovadoras e com baixo risco (BENNET; COOPER, 1979; 1981), contribuindo para a sobrevivência das empresas em épocas de crise econômica (NAIDOO, 2010).

No Brasil, além dos dados da OECD, a PINTEC - Pesquisa de Inovação Tecnológica dissemina resultados relacionados à área de inovação. A PINTEC é uma pesquisa-satélite do Sistema de Estatísticas Econômicas e coleta informações para a construção de indicadores das atividades de inovação tecnológica das empresas brasileiras, por meio do IBGE - Instituto Brasileiro de Geografia e Estatística. A PINTEC segue as recomendações do Manual de Oslo, no qual define a inovação como a implementação de produtos (bens ou serviços) ou processos 
novos ou substancialmente aprimorados. A pesquisa produz informações sobre os gastos com atividades inovativas, os obstáculos encontrados nas atividades de inovação, as inovações organizacionais e de marketing, entre outros (PINTEC, 2010).

A PINTEC considera uma inovação de marketing, em consonância com a OECD (2005) e Higgins (1995), quando ocorre a implementação de um novo método de marketing com mudanças significativas na concepção do produto ou em sua embalagem (desde que não altere suas características funcionais), no posicionamento do produto, promoção ou fixação de preços, através da abertura de novos mercados ou reposicionamento do produto, buscando responder as necessidades dos clientes (PINTEC, 2010). A pesquisa divulgada em 2010 coloca que em relação às inovações de marketing, as estratégias diferenciadas da indústria e dos serviços se sobressaíram, sendo na indústria 45,8\% das novidades estavam ligadas à estética, desenho ou outras mudanças; nos serviços $43,6 \%$ consideram como primordial a adoção de novos conceitos e estratégias de marketing.

Deste modo, as empresas que estão implementando inovações de produtos e processos originais tendem a utilizar com mais frequência as informações geradas pelas instituições de produção de conhecimento tecnológico: universidades, centros de ensino superior, institutos de pesquisa, entre outros (PINTEC, 2010).

\subsection{A Prática do Marketing de Relacionamento}

O marketing de relacionamento teve sua origem no marketing de serviços a partir de 1970, quando pesquisadores começaram a desenvolver teorias enfocando o relacionamento entre compradores e vendedores, pois a estratégia de marketing-mix não conceituava o relacionamento com o cliente (MÖLLER; HALINEN, 2000).

Atualmente, a expressão marketing de relacionamento é frequentemente citada, e sua definição vem sendo ampliada com adição de novos elementos (MILAN, 2004), sendo considerado como um fenômeno que parte do pressuposto de uma interação entre os parceiros de longo prazo, estabelecendo e mantendo trocas relacionais bem sucedidas. Essas trocas levam para uma maior criação de valor de mercado, beneficiando ambas as partes, em um processo contínuo de se engajar em atividades colaborativas (PARVATIYAR; SHETH, 2000).

O marketing de relacionamento, segundo a visão da escola nórdica, é um processo de identificar e estabelecer, manter, melhorar e quando necessário terminar relacionamentos com clientes e outras partes interessadas, com lucro, de modo que os objetivos de todas as partes 
envolvidas estejam satisfeitos, através de uma doação recíproca, com confiança e sendo cumpridas as promessas (GRÖNROOS, 1996). Ainda, de acordo com esta escola, o gerenciamento dos serviços está no cerne da construção e na manutenção dos relacionamentos, podendo ter como pilares principais a abordagem de redes ou a aliança estratégica (GRÖNROOS, 2000).

Assim sendo, o sucesso do marketing de relacionamento pode estar associado à confiança e ao compromisso, dois constructos que prezam pela interação entre as partes através da cooperação, reduzindo riscos e evitando a troca para alternativas de curto prazo (MORGAN; HUNT, 1994). Nesse sentido, o processo de construção de relacionamentos de longo prazo se torna difícil de ser reproduzido por outros atores (MORGAN; HUNT, 2000). A lealdade, confiança e reputação não podem ser transferidos e nem estão à venda no mercado, por isso, relacionamentos estabelecidos são possíveis fontes de vantagem competitiva. Vantagens competitivas únicas, sustentáveis e inimitáveis provavelmente serão resultado de relacionamentos nos canais com atributos de confiança, comprometimento, coordenação e espírito de cooperação (MACADAR, 2004).

Sendo assim, o marketing de relacionamento pode ser visto como um investimento em relacionamento e expertise do vendedor com efeito imediato sobre as vendas, tornando-se mais eficaz quando os relacionamentos são mais críticos na oferta de serviços ao invés de produtos aos clientes (PALMATIER et al., 2006). Dessa forma, pode-se citar, como principais benefícios do marketing de relacionamento, além da retenção de clientes, a redução de custos e maiores lucros (BERRY, PARASURAMAN, 1991). Por isso, manter clientes pode ter impacto positivo na rentabilidade da empresa, em tempos em que é difícil, ou até possui um custo elevado, encontrar novos clientes para substituir os ex-clientes lucrativos (GRÖNROOS, 2004).

Transpondo esses conceitos para as IES, constata-se que após décadas de massificação, onde as universidades entregaram produtos praticamente iguais, o setor está passando a utilizar outras oportunidades (NUNES et al., 2008), evoluindo para o foco no cliente, nos custos e na conveniência, onde os métodos de pesquisa de marketing, diferenciação de preço e marketing de relacionamento se tornam alguns dos exemplos de práticas gerenciais emergentes nas IES (KALSBEK, 2000). 


\subsection{Ensino Superior}

A história do ensino superior no Brasil é recente em comparação ao ensino superior europeu, onde das tradicionais universidades a mais antiga que se tem relato é a Universidade de Bologna, fundada em 1088 (NUNES, 2009). No Brasil o ensino começou a ser difundido a partir de 1808 com a vinda da família real portuguesa (AFONSO, 2005) e as primeiras universidades tiveram origem com as Academias Reais Militares que, mais tarde, originaram a Universidade Federal do Rio de Janeiro e a Universidade Federal da Bahia (NUNES, 2009).

Entre as décadas de 1920 até 1990 ocorreram mudanças no sistema educacional, como a reforma proposta por Getúlio Vargas (AFONSO, 2005) e a criação da primeira Lei de Diretrizes e Bases (LDB) a qual disciplinou a organização e o funcionamento do ensino brasileiro (SILVA, 2008). Mas, a partir de 1994 foram as instituições privadas que passaram a responder pela maior parte dos matriculados no ensino superior, com um aumento vertiginoso de mais de dois milhões e meio de matriculados de 1994 a 2007 (NUNES, 2009).

Este acentuado crescimento de matrículas no ensino superior tem influência do capital privado combinado com fatores externos entre os quais está a facilidade de abertura de novos cursos e instituições, através da segunda LDB sendo sancionada em 1996; a regulamentação do dispositivo legal que permitiu a existência de (IES) constituídas de empresas com finalidades lucrativas, em 1999; o ingresso de uma parcela da população que constituía uma demanda reprimida, entre os anos de 1996 e 2002; e, o ingresso tardio no ensino superior de pessoas provenientes da população economicamente ativa (PEA) que já haviam concluído o ensino médio há cinco anos ou mais (NUNES, 2009).

Diversas faculdades ascenderam ao nível de centros universitários e estes em universidades nos anos de 1995 e 1996 (INEP, 1996). Em sua grade de expansão produtomercado, uma das estratégias de crescimento intensivo foi a penetração de mercado caracterizada pelas mudanças dos canais de distribuição e ampliação da área de cobertura geográfica (ANSOFF,1957). Com base neste contexto, destaca-se a estratégia multicampi das IES, ampliando a oferta de cursos e de vagas (NUNES, 2009).

Diante disso, nos últimos anos, as inovações em serviços educacionais oscilou entre o nível macro do sistema educacional e o nível micro da sala de aula (NÓVOA, 1995). Assim, as instituições de ensino não podem ser consideradas como empresas comuns (MICHAEL, 2004), uma vez que criar inovação é conceber e implementar reformas estruturais do sistema educativo (nível macro) (SEVERO et al., 2011). 
Entretanto, atualmente, as inovações em serviços educacionais e em ensino podem ser implantadas e desenvolvidas no contexto da organização escolar. Abrange criar condições organizacionais para que a inovação aconteça, para que os docentes e discentes se sintam motivados e gratificados em participar das inovações (NÓVOA, 1995), destacando todos como parte responsável pela inovação.

Alguns fatores básicos promovem a inovação no ensino, que passam por equipes docentes sólidas e comunidade educativa receptiva; rede de cooperação e de intercâmbio, assessores críticos e outros apoios externos; proposta da inovação e a mudança dentro de um contexto cultural; ambiente de confiança e de bem-estar, comunicação intensa nas relações interpessoais; institucionalização da inovação; criação de oportunidades para que as inovações possam ser vividas com intensidade, refletidas em profundidade e avaliadas com exatidão (CARBONELL, 2002). Ou seja, as IES precisam entender e absorver o processo de inovação para poder exercitá-lo e estimulá-lo no dia-a-dia dos discentes e dos docentes (CARVALHO, 1998).

Uma inovação no sistema de ensino parte das necessidades internas do quadro docente, não advém de mandatos administrativos ou institucionais, corroborando com a visão neoschumpeteriana em que o empreendedor não é a única mola propulsora de inovação (HERNÁNDEZ et al., 2000). A inovação no sistema de ensino é concebida à medida que se busca dar respostas à preocupação proveniente de uma prática que não satisfaz às expectativas dos docentes e dos discentes (SEVERO et al., 2011).

\section{METODOLOGIA}

Este estudo se caracteriza com uma pesquisa qualitativa, de caráter exploratório, desenvolvida a partir de um estudo de casos múltiplos, a qual explora uma situação, baseando-se em pequenas amostras não representativas, onde os dados não são analisados estatisticamente (YIN, 2009; HAIR Jr.; BUSH; ORTINAU, 2000; VERGARA, 2006). Especificamente esta pesquisa abrange três IES, comparando o foco das inovações de marketing.

Os meios de investigação utilizados para a coleta de dados envolveram a pesquisa documental e a entrevista individual em profundidade, com uma abordagem semiestruturada, (MALHOTRA, 2006), mediante a aplicação de um roteiro básico de questões, o qual foi estruturado a partir do questionário utilizado na PINTEC (2010), sendo a técnica que melhor se adaptou ao contexto metodológico da presente pesquisa 
Em termos de pesquisa documental, foram consultados alguns documentos das IES relacionados ao seu Planejamento Estratégico, ao seu Projeto de Desenvolvimento Institucional (PDI), pesquisas de satisfação dos alunos e o relatório do perfil social da IES. As entrevistas individuais em profundidade, por sua vez, ocorreram no mês de novembro de 2011, entrevistando-se o gestor responsável pela implementação da inovação de marketing (Direção e Coordenação de Marketing) das IES estudadas. As entrevistas foram gravadas por meio de áudio, bem como foram realizadas anotações de campo. O tempo médio de cada entrevista foi de cerca de 1 hora. Posteriormente, para facilitar o processo de análise e interpretação, as entrevistas foram transcritas, conferidas com versão em áudio como forma de proporcionar precisão, fidelidade e interpretação dos dados (FLICK; 2004; GIBBS, 2009).

Para a análise e interpretação dos dados coletados, o método utilizado se deu de acordo com a Análise de Conteúdo, que consiste em levantar os elementos que permitem a apreciação das comunicações e fornecem informações suplementares (BARDIN, 2004). Nesse sentido, utilizaram-se as categorias a priori embasadas no referencial teórico e nos objetivos desta pesquisa: i) inovações em marketing; ii) setores envolvidos; iii) marketing de relacionamento; iv) ineditismo no Brasil; v) novas tecnologias e/ou novos métodos; vi) inovação aberta ou fechada; vii) benefícios com a inovação; viii) implicações com relação às dificuldades encontradas.

Para a validação dos dados coletados, realizou-se a triangulação entre as entrevistas e os documentos fornecidos pelas IES. Para manter a confiabilidade, dois pesquisadores verificaram a transcrição das entrevistas seguindo as recomendações para a metodologia de pesquisa qualitativa (GIBBS, 2009). No aspecto de confidencialidade, as IES, por questões estratégicas, reservaram-se ao direito de não divulgar as suas razões sociais e marcas. Sendo assim, doravante neste estudo, as mesmas serão denominadas como F1, F2 e F3.

\section{RESULTADOS E DISCUSSÕES}

Esta pesquisa foi realizada em três IES (Quadro 1) com unidades de educação na Serra Gaúcha. Estas IES possuem portes diferentes, sendo que a F1 possui 10 cursos de graduação, contando com menos de 50 colaboradores (professores e funcionários administrativos), com 500 alunos na unidade de Caxias do Sul. As F2 oferece 6 cursos de graduação e 4 de pósgraduação, com cerca de 100 colaboradores e 500 alunos. Já a F3 possui 7 cursos de graduação e 6 cursos de pós-graduação, com cerca de 100 colaboradores, atendendo cerca de 500 alunos em 2011. A IES F1 é classificada como Universidade e pretende expandir a 
quantidade de unidades educacionais no Brasil nos próximos anos. e pretende expandir a quantidade de unidades educacionais no Brasil nos próximos anos. As F2 e F3 são Faculdades e com base no Planejamento Estratégico destas, bem como nos PDIs de cada IES, observou-se que estas se preparam para implantar novos cursos de graduação, mas não há planos de desenvolverem novas unidades educacionais.

Com base no Planejamento Estratégico e no PDI das IES pesquisadas, evidencia-se que estas apresentam em comum o desenvolvimento cultural e a geração do conhecimento das diferentes áreas onde atuam. Para tanto, as três IES desenvolvem parcerias com outras instituições de ensino, sindicatos, associações da comunidade e outros stakeholders como, por exemplo, empresas da indústria, comercio e serviços. A F1 se destaca das demais por manter associações com 13 IES fora do Brasil, enquanto que a F2 tem parcerias com 3 IES de fora do Brasil. A F3, por sua vez, não apresenta associação com IES fora do Brasil, mas admite que está trabalhando para que em 2012 finalize o processo de parceria com duas universidades do Chile

A pesquisa realizada nas três IES foi embasada em questões abertas, aplicadas aos seus gestores, sendo que, por meio da análise de conteúdo, foram identificadas as seguintes categorias ou dimensões de análise: i) a descrição das principais inovações em marketing nos anos de 2010 e 2011; ii) os setores envolvidos nas inovações de marketing; iii) o impacto das inovações sobre o marketing de relacionamento; iv) a ocorrência de ineditismo no Brasil; v) o processo de inovação aberto ou fechado; ; vi) a utilização de novos métodos e/ou novas tecnologias na inovação; vi) benefícios gerados a partir das inovações; vii) implicações relacionadas às dificuldades durante e após a implantação das inovações em marketing. Estas categorias estão apresentadas no decorrer deste trabalho (Quadro 2, 3 e 4).

\subsection{Inovações em marketing e setores envolvidos}

A partir das entrevistas individuais em profundidade, identificaram-se as principais inovações nas IES pesquisadas. Na F1 as inovações encontradas (Quadro 2) foram: i) mudanças na comunicação através de materiais impressos, focando mais no perfil profissional dos egressos dos cursos; ii) flexibilização da presença dos alunos em sala de aula, com acesso via ambiente virtual, para facilitar o acesso às aulas e evitar que os alunos evadissem por falta de tempo para acessar os materiais de aula; iii) separação das campanhas publicitárias de Graduação e Pós-graduação, intercalando-as. Esta inovação permitiu que maior foco dos vendedores na busca de novos alunos. 
Entre as inovações de marketing observadas na F1 observa-se que estas envolvem o setor de Ensino (Quadro 2), o que demonstra a preocupação da IES com o alinhamento estratégico do negócio, o qual foi observado no PDI e evidenciado na entrevista realizada com o principal gestor da unidade educacional, o qual expressa que o diferencial da IES está em prestar um serviço educacional de alta qualidade, através de aulas planejadas, professores habilitados (mestres e doutores) e materiais de apoio (livros impressos e material digital) especialmente desenvolvidos para as disciplinas.

Na F2 destacam-se as inovações em marketing (Quadro 3): i) identificação do perfil dos alunos da IES, através de uma pesquisa com as fases qualitativa e a quantitativa, que teve o objetivo de identificar desejos profissionais, fatores motivadores e dificultadores que influenciam no fato de estar estudando, bem como levantar o perfil socioeconômico dos alunos e os motivos que os levaram a escolher a IES; ii) divulgação da IES com a utilização do Google adwors, para ampliar a exposição da IES na internet; iii) comunicação com os alunos e comunidade através das Redes Sociais e de uma Ambiente Virtual de Aprendizagem; iv)estruturação do setor de Marketing e Vendas; v) mudança no logotipo utilizado para expressar a marca da IES. Esta mudança foi necessária pela alteração no nome da IES.

Os entrevistados da F2 (Diretor da IES e Coordenador de Marketing) afirmam que a mudança de mantenedores implantou na IES um novo posicionamento estratégico, fazendo com que a faculdade trabalhasse um público que busca facilidades de acesso ao ensino, com preços mais baixos e qualidade satisfatória. Anteriormente a faculdade trabalhava um público que apresentava uma maior capacidade de pagamento e exigia serviços diferenciados e, gradativamente desde 2009, a IES vem alterando o perfil dos cursos de graduação para oferecer serviços educacionais que atendam o novo nicho escolhido. Portanto, o papel da Direção e do setor de Marketing foi ampliado, já que trabalha os conflitos gerados pela mudança de posicionamento da IES, nos alunos e nos colaboradores (professores e funcionários).

NA F3 foram identificadas inovações em marketing (Quadro 4) relacionadas a: i)mudança da forma de apresentar a IES, através de um vídeo institucional que demonstra as áreas de atuação dos cursos oferecidos. Utilização de relatos de empresários e profissionais de reconhecido sucesso na região; ii) comunicação e interação com os alunos através das Redes Sociais. Este canal de comunicação é utilizado para divulgar eventos e noticias, realizar pesquisas de opinião, ouvir sugestões e reclamações, bem como divulgar a IES; iii) mudança significativa no conceito da Campanha de Vestibular, focando na qualificação do profissional 
oriundo da IES. Dentro do novo conceito foram divulgados os benefícios de cada profíssão oriunda dos cursos de graduação; iv) estruturação de um núcleo de apoio ao estudante, para desenvolver cursos de aperfeiçoamento para os estudantes, servir como central de ouvidoria e atendimento psicopedagógico ao aluno e professores; v) programa de atração e retenção de alunos. Este programa foi desenvolvido para identificar os motivos que levam os alunos a evadirem e os motivadores que levaram os alunos a permanecer na IES. Este programa gerou ações de retenção e influenciou na mudança de conceito das campanhas de vestibular.

Para a pesquisa realizada na IES F3 entrevistou-se a Direção da Unidade e a Coordenação de Marketing, os quais afirmaram que a IES está em um processo de construção da identidade da marca, ou seja, a IES ainda busca entender o perfil de alunos que atende e os serviços que estes necessitam para ampliar a satisfação. Neste sentido a IES realiza: i)pesquisa quantitativa de levantamento de perfil, a qual é aplicada no momento da matricula; ii) pesquisa de satisfação dos serviços educacionais e de apoio, aplicado semestralmente; iii)pesquisa realizada junto aos alunos de ensino médio para identificar as expectativas de estudos na graduação.

Avaliando-se as principais inovações em marketing das três IES estudas (Quadro 5), observa-se que todas instituições buscam melhorar a comunicação e o atendimento dos alunos, o que expressa o intuito das instituições em melhorar o relacionamento com o aluno através de serviços complementares. Entre as IES estudadas, a F2 e F3 buscaram meios alternativos de comunicação, utilizando-se de Redes Sociais e estruturas administrativas/pedagógicas de atendimento, enquanto que a F1 destacou-se pelo desenvolvimento de novas possibilidades do aluno ter contato com a aula, mesmo quando está impossibilitado de comparecer a unidade educacional.

\subsection{Ineditismo e abertura nas inovações em marketing}

As inovações em marketing identificadas na F1 (Quadro 2) resultaram na melhoria da relação com os fornecedores, que melhoraram a previsão de entrega de materiais de campanha publicitária. Ainda se observou uma melhoria no atendimento aos alunos com relação à necessidade de flexibilidade de acesso às aulas, pois com a virtualização dos materiais os alunos aumentaram a liberdade de horários e meios de acesso. As inovações em marketing da F1 já existiam no Brasil e o processo de inovação ocorreu de forma fechado, pois estas foram desenvolvida com a participação dos setores de Marketing, Ensino e de Tecnologia de Informação, que apenas viabilizou os meios para ocorrer as mudanças. 
Para os entrevistados da F2 (Quadro 3), esta desenvolveu melhorias nos processo de relacionamento com os alunos, oferecendo serviços segmentados para o público atendido pela IES, ampliando o raio de atuação, atingindo mais pessoas interessadas em graduação. Outra inovação trata da alteração de posicionamento da IES, que por consequência, modificou a identidade visual da faculdade. A F2 sob o ponto de vista do ineditismo apresenta inovações já existentes no Brasil e entre as cinco inovações apresentadas, três destas são essencialmente fechadas, ou seja estas foram desenvolvidas por agentes internos e com pequena colaboração de fornecedores. Duas das inovações em marketing foram desenvolvidas com a participação efetiva de agentes externos, desde a elaboração do projeto até a execução, além de contar com a colaboração dos setores de Direção, Marketing e Tecnologia da Informação.

$\mathrm{Na}$ F3, entre as cinco inovações em marketing descritas, destacou-se o programa de atração e retenção de alunos, o qual trata em profundidade o tema do marketing de relacionamento, pois efetivamente trabalha na identificação do perfil de possíveis alunos, levanta o perfil dos alunos matriculados e investiga os motivos de saída e mesmo os fatores que os mantêm estudando na IES, com estas informações desenvolve serviços, cursos e auxilia o aluno a manter-se estudando e melhorando a sua performance acadêmica. As inovações encontradas, em geral, buscam melhorar o relacionamento com os alunos e baseiam-se nas melhorias dos processos de comunicação.

Observa-se que na F3 apenas a inovação relacionada ao novo conceito de apresentação da instituição, através de um vídeo, não foi identificado no Brasil iniciativas, enquanto que as demais inovações já existiam no País. Três inovações são consideradas fechadas, desenvolvidas essencialmente por agentes internos e as demais inovações relatadas podem ser consideradas abertas, com a participação de agentes externos.

Analisando as inovações encontradas nas IES pesquisadas (Quadro 5), sob o caráter do ineditismo e da abertura do processo de inovação, nota-se que apenas a F3 citou uma inovação que a própria IES não encontrou algo similar no Brasil, demonstrando que estas instituições estão aquém da fronteira da inovação de marketing no Ensino Superior, limitando-se a replicador os métodos já existentes. Constata-se na pesquisa a evidência de que a maioria das inovações são produzidas de forma fechada ou com pouca abertura, pois na maioria dos casos ocorreu pouca participação de agentes externos.

Ainda avaliando as três IES pesquisadas observa-se que as inovações estão direcionadas ao marketing de relacionamento, pois tratam de mudanças significativas em processos e conceitos que levam ao estreitamento das relações com os clientes (alunos) e/ou 
com fornecedores, e este é o principal foco das três IES encontrados nos documentos analisados (entrevistas, Planejamento Estratégico e PDI), os quais estão desdobrados em ações nas instituições.

\subsection{Novas tecnologias, benefícios e implicações provenientes das inovações}

No que tange às novas tecnologias e métodos, a F1 utilizou nas três principais inovações (Quadro 2) softwares para viabilizar as inovações. Entre os benefícios destaca-se a melhoria da qualidade do material impresso, o aumento da satisfação dos alunos e melhorias no processo de comunicação. Estas inovações em marketing implicaram em aumento dos custos de produção de material de campanha publicitária e incialmente ocorreu alguma resistência dos colaboradores que rapidamente foi superada.

A F2 (Quadro 3) demandou a adoção de software em quatro das cinco inovações em marketing, para viabilizar tecnicamente aos novos processos de relacionamento com os alunos. Entre as inovações relatadas destaca-se o desenvolvimento de um Ambiente Virtual de Aprendizagem e a utilização das Redes Sociais, que alterou significativamente o processo de comunicação com os alunos e o ensino/aprendizagem, pois anteriormente a comunicação ocorria por outros meios e o ensino só ocorria de forma presencial. Com novos meios de comunicação, utilizando a nova tecnologia foi possível criar atividades de aprendizado a distância, flexibilizando o ensino. Os benefícios advindos das inovações encontradas na F2 (Quadro 4) estão relacionados à otimização dos recursos, o aumento da procura de novos alunos em relação aos vestibulares anteriores e maior velocidade de atendimento às demandas dos alunos. Em relação às implicações, observa-se que houveram poucas dificuldades, todas rapidamente resolvidas.

Para implantar as inovações identificadas na IES F3 (Quadro 4) utilizou-se softwares em duas inovações e nas outras basicamente foram desenvolvidos novos métodos, principalmente direcionados ao relacionamento com os alunos. Os benefícios estão relacionados as melhorias de comunicação, a aproximação do aluno e IES, bem como ao aumento da acertividade no desenvolvimento de programas de aperfeiçoamento de estudos oferecidos aos alunos, o que resultou em maior satisfação dos estudantes em relação aos serviços educacionais. Não foi percebido maiores dificuldades na implantação das inovações.

Analisando as três IES pesquisadas (Quadro 5) nota-se que as inovações relatadas nas entrevistas utilizam poucas tecnologias novas, valendo-se de melhorias em métodos e novos processos, que resultaram em benefícios de qualidade e em alguns casos a redução de custos, 
sobretudo as inovações ampliaram o raio de atuação das IES e aumentaram a captação de novos alunos em relação aos anos anteriores. Observa-se que em relação às implicações as três IES apresentaram dificuldades iniciais na implantação das mudanças, mas que foram rapidamente resolvidas. Nas entrevistas evidenciou-se que a utilização de novos softwares gerou inicialmente alguma dificuldade, que foram resolvidas com a capacitação dos usuários, para minimizar a insatisfação gerada pela mudança na adoção das inovações.

\section{CONSIDERAÇÕES FINAIS}

Esta pesquisa ocorreu em três IES que estão inseridas em um contexto de uma próspera região, a qual detém o segundo maior PIB do interior do Estado do Rio Grande do Sul (FEE, 2011) e que suporta 24 IES, sendo 14 faculdades (MEC, 2011), que oferecem cursos superiores em diferentes especialidades. Este cenário competitivo é motivador de inovações em marketing relacionados ao ensino e aos serviços de suporte, pois a inovação agrega valor ao serviço e pode diferenciar as organizações frente aos concorrentes.

Baseando-se nos objetivos deste estudo, no sentido de identificar e descrever as inovações em marketing, ocorridas nos anos de 2010 e 2011, em três IES da Serra Gaúcha, em relação às áreas de ensino e serviços de suporte, identificou-se que o principal foco das inovações está ligado aos processos de comunicação e suporte aos alunos, o que evidencia uma grande preocupação das IES em melhorar o relacionamento com o aluno através dos serviços complementares e disponibilização de novos canais de comunicação.

Observa-se que na dimensão do marketing de relacionamento a IES F1 inova o método de ensino de maneira significativa, ao disponibilizar meios alternativos para o aluno acessar as aulas quando não é possível participar de presencialmente, esta nova situação permitiu a manutenção do contato do aluno com a IES, mesmo quando está impossibilitado de estar fisicamente nas aulas, que neste caso criou uma conexão, ampliando o relacionamento entre a Universidade e o estudante. A F2 e F3 se destacam pela inovação no atendimento das demandas dos alunos através de ambientes virtuais e redes sociais, aproximando o aluno, contribuído para a qualidade do relacionamento, o que refletiu em maior satisfação dos alunos e o aumento de novos alunos nas Faculdades.

Ao avaliar o ineditismo no Brasil e abertura das inovações em marketing, nota-se que apenas a F3, afirma que apresentou uma inovação sem similaridade no país, evidenciando que estas instituições de ensino estão aquém da fronteira da inovação, reproduzindo métodos e conceitos já existentes. Com relação à abertura das inovações, estas foram desenvolvidas com 
pouca participação de agentes externos, em um processo inovativo fechada ou com o mínimo de abertura. Observa-se ainda que ocorreram inovações em métodos e conceitos, com pouca introdução de novas tecnologias de software e nenhuma de hardware.

Quanto aos benefícios provenientes das inovações referem-se à melhoria na comunicação com alunos e com os fornecedores, à melhoria na qualidade de serviços de suporte e ao aumento da abrangência de atuação das IES. Os benefícios relativos ao relacionamento com os alunos foram evidenciados nas pesquisas semestrais de satisfação dos alunos, que registraram melhoras nas questões que abordavam o tema. Sobre as implicações observa-se que as três IES apresentaram algumas dificuldades iniciais na implantação das mudanças, as quais foram resolvidas rapidamente.

Entre os principais elementos da inovação de marketing encontrados na pesquisa, destaca-se que as IES primam pela melhoria de processos de comunicação, desenvolvendo novos canais de contato com clientes e fornecedores. Outra tônica encontrada nas inovações são as melhorias em processos de suporte, que agilizam e ampliam os serviços prestados. Este estudo esclarece que as IES não desenvolvem inovações com alto nível de ineditismo, assim como a abertura no processo inovador não é praticada frequente, portanto mesmo nestas instituições com excelentes avaliações de qualidade, mantendo mais de $80 \%$ do quadro de professores composto por mestres e doutores ainda necessitam desenvolver a sistematização de processos inovadores que promovam mudanças profundas e que ocorra maior participação de agentes externos a instituição.

A pesquisa limita-se a explorar e descrever a realidade das inovações encontradas em três IES da Serra Gaúcha, o que pode estimular a realização de estudos futuros sobre a inovação de marketing em serviços educacionais em outras IES da região. Ainda em acréscimo, sugere-se a realização de pesquisas que enfoquem a comparação entre os perfis inovadores das IES entre regiões. 


\section{APÊNDICES}

\begin{tabular}{|c|c|c|c|c|c|c|c|}
\hline $\begin{array}{c}\text { Instituição de } \\
\text { Ensino Superior } \\
\text { (IES) } \\
\end{array}$ & $\begin{array}{l}\text { Cursos de } \\
\text { Graduação }\end{array}$ & $\begin{array}{l}\text { Cursos de Pós- } \\
\text { Graduação }\end{array}$ & $\begin{array}{c}\text { Quantidade de } \\
\text { Alunos na Unidade }\end{array}$ & $\begin{array}{l}\text { Quantidade de } \\
\text { Professores e } \\
\text { Funcionários } \\
\end{array}$ & $\begin{array}{c}\text { Quantidade de } \\
\text { Unidades de } \\
\text { Ensino } \\
\end{array}$ & $\begin{array}{c}\text { Atuação na } \\
\text { Serra Gaúcha }\end{array}$ & $\begin{array}{l}\text { Associações com } \\
\text { outras IES }\end{array}$ \\
\hline F1 & $\begin{array}{l}10 \text { cursos nas áreas } \\
\text { de negócios e } \\
\text { licenciatura }\end{array}$ & $\begin{array}{l}37 \text { cursos nas } \\
\text { áreas educacional, } \\
\text { empresarial, } \\
\text { jurídica, pública, } \\
\text { saúde, engenharia } \\
\text { e meio ambiente. }\end{array}$ & $\begin{array}{l}\text { Em Caxias: na faixa } \\
\text { de } 500 \text { a } 1.000 \\
\text { alunos. } \\
\text { Brasil: } 140 \text { mil } \\
\text { alunos. }\end{array}$ & $\begin{array}{l}\text { Em Caxias: na } \\
\text { faixa até } 49 \\
\text { colaboradores. } \\
\text { Brasil: de } 1300 \text { a } \\
1500 \\
\text { colaboradores. }\end{array}$ & $\begin{array}{l}\text { Em Caxias: } 01 \\
\text { unidade de ensino. } \\
\text { Brasil: } 412 \\
\text { unidades. }\end{array}$ & $\begin{array}{l}\text { Atua na Serra } \\
\text { Gaúcha a mais } \\
\text { de } 7 \text { anos. }\end{array}$ & $\begin{array}{l}\text { Mantêm associação } \\
\text { com } 13 \text { IES fora do } \\
\text { Brasil, realizando } \\
\text { intercâmbio de } \\
\text { estudos. }\end{array}$ \\
\hline F2 & $\begin{array}{l}6 \text { cursos nas áreas } \\
\text { de negócios, } \\
\text { design, } \\
\text { comunicação, } \\
\text { relações políticas e } \\
\text { internacionais. }\end{array}$ & $\begin{array}{l}5 \text { cursos nas áreas } \\
\text { de saúde, design e } \\
\text { negócios. }\end{array}$ & $\begin{array}{l}\mathrm{Na} \text { faixa de } 500 \mathrm{a} \\
1.000 \text { alunos. }\end{array}$ & $\begin{array}{l}\text { Na faixa de } 50 \text { a } \\
100 \text { colaboradores. }\end{array}$ & $\begin{array}{l}02 \text { unidades de } \\
\text { ensino, em } \\
\text { diferentes } \\
\text { municípios do Rio } \\
\text { Grande do Sul. }\end{array}$ & $\begin{array}{l}\text { Atua na Serra } \\
\text { Gaúcha a } 6 \\
\text { anos. }\end{array}$ & $\begin{array}{l}\text { Mantêm associação } \\
\text { com } 3 \text { IES fora do } \\
\text { Brasil, realizando } \\
\text { intercâmbio de } \\
\text { estudos. }\end{array}$ \\
\hline F3 & $\begin{array}{l}7 \text { cursos nas áreas } \\
\text { de tecnologia da } \\
\text { informação, design, } \\
\text { qualidade, negócios } \\
\text { e construção civíl. }\end{array}$ & $\begin{array}{l}6 \text { cursos nas áreas } \\
\text { de negócios, } \\
\text { qualidade, design } \\
\text { e tecnologia da } \\
\text { informação. }\end{array}$ & $\begin{array}{l}\text { Na faixa de } 500 \text { a } \\
1.000 \text { alunos. }\end{array}$ & $\begin{array}{l}\text { Na faixa de } 50 \text { a } \\
100 \text { colaboradores. }\end{array}$ & $\begin{array}{l}02 \text { unidades de } \\
\text { ensino, em } \\
\text { diferentes } \\
\text { municípios do Rio } \\
\text { Grande do Sul. } \\
\end{array}$ & $\begin{array}{l}\text { Atua na Serra } \\
\text { Gaúcha a } 3 \\
\text { anos. }\end{array}$ & $\begin{array}{l}\text { Mantêm associação } \\
\text { com IES dentro do } \\
\text { Brasil, dividindo } \\
\text { conhecimentos e } \\
\text { espaços pedagógicos. }\end{array}$ \\
\hline
\end{tabular}

Quadro 1 Perfil das IES

Fonte: Dados provenientes da pesquisa (2011). 


\begin{tabular}{|c|c|c|c|c|c|c|c|}
\hline Inovações & $\begin{array}{l}\text { Setores } \\
\text { Envolvidos }\end{array}$ & $\begin{array}{l}\text { Marketing de } \\
\text { Relacionamento } \\
\end{array}$ & $\begin{array}{l}\text { Ineditismo } \\
\text { no Brasil }\end{array}$ & $\begin{array}{l}\text { Abertura da } \\
\text { Inovação }\end{array}$ & $\begin{array}{l}\text { Novas Tecnologias } \\
\text { / Método }\end{array}$ & Benefícios & Implicações \\
\hline $\begin{array}{l}\text { Mudanças na } \\
\text { comunicação } \\
\text { através de } \\
\text { materiais } \\
\text { impressos. }\end{array}$ & $\begin{array}{l}\text { Marketing e } \\
\text { Ensino. }\end{array}$ & $\begin{array}{l}\text { Os fornecedores e os } \\
\text { setores de vendas tiveram } \\
\text { que se adaptar aos prazos } \\
\text { das campanhas. }\end{array}$ & $\begin{array}{l}\text { Existe em } \\
\text { outras IES no } \\
\text { Brasil. }\end{array}$ & $\begin{array}{l}\text { Inovação fechada. } \\
\text { Envolvimento do } \\
\text { setor de } \\
\text { Marketing. }\end{array}$ & $\begin{array}{l}\text { Novo software de } \\
\text { gerenciamento da } \\
\text { logística. }\end{array}$ & $\begin{array}{l}\text { Melhoria na } \\
\text { qualidade do } \\
\text { material impresso } \\
\text { e no material } \\
\text { digital }\end{array}$ & $\begin{array}{l}\text { Aumento dos } \\
\text { custos com a } \\
\text { produção dos } \\
\text { materiais } \\
\text { impressos. }\end{array}$ \\
\hline $\begin{array}{l}\text { Flexibilização } \\
\text { da presença dos } \\
\text { alunos em sala } \\
\text { de aula, com } \\
\text { acesso via } \\
\text { ambiente } \\
\text { virtual. }\end{array}$ & $\begin{array}{l}\text { Ensino, } \\
\text { Marketing e } \\
\text { Tecnologia da } \\
\text { Informação. }\end{array}$ & $\begin{array}{l}\text { O aluno escolhe a forma } \\
\text { que deseja assistir sua aula } \\
\text { o que provocou um } \\
\text { aumento da satisfação. }\end{array}$ & $\begin{array}{l}\text { Existe em } \\
\text { outras IES no } \\
\text { Brasil. }\end{array}$ & $\begin{array}{l}\text { Inovação fechada. } \\
\text { Envolvimento do } \\
\text { setor de Ensino. }\end{array}$ & $\begin{array}{l}\text { Novo software de } \\
\text { plataforma de } \\
\text { aprendizado virtual } \\
\text { e novo método para } \\
\text { o controle de } \\
\text { frequência do } \\
\text { aluno. }\end{array}$ & $\begin{array}{l}\text { Aumento da } \\
\text { satisfação dos } \\
\text { alunos. }\end{array}$ & $\begin{array}{l}\text { Resistência inicial } \\
\text { dos colaboradores } \\
\text { com o novo } \\
\text { método. }\end{array}$ \\
\hline $\begin{array}{l}\text { Separação das } \\
\text { campanhas } \\
\text { publicitárias de } \\
\text { Graduação e } \\
\text { Pós-graduação, } \\
\text { intercalando-as. }\end{array}$ & $\begin{array}{l}\text { Marketing e } \\
\text { Ensino. }\end{array}$ & $\begin{array}{l}\text { Alteração do planejamento } \\
\text { dos fornecedores para } \\
\text { garantir a entrega do } \\
\text { material didático e digital } \\
\text { dentro dos novos prazos. }\end{array}$ & $\begin{array}{l}\text { Existe em } \\
\text { outras IES no } \\
\text { Brasil. }\end{array}$ & $\begin{array}{l}\text { Inovação fechada. } \\
\text { Envolvimento do } \\
\text { setor de Ensino e } \\
\text { Marketing. }\end{array}$ & $\begin{array}{l}\text { Novo software de } \\
\text { gerenciamento da } \\
\text { logística. }\end{array}$ & $\begin{array}{l}\text { Melhoria nos } \\
\text { processos de } \\
\text { comunicação e } \\
\text { vendas, } \\
\text { diferenciando o } \\
\text { trabalho nas } \\
\text { campanhas. }\end{array}$ & $\begin{array}{l}\text { Aumento dos } \\
\text { custos com as } \\
\text { campanhas. }\end{array}$ \\
\hline
\end{tabular}

Quadro 2 Inovações em marketing da F1

Fonte: Dados provenientes da pesquisa (2011). 


\begin{tabular}{|c|c|c|c|c|c|c|c|}
\hline Inovações & $\begin{array}{l}\text { Setores } \\
\text { Envolvidos }\end{array}$ & $\begin{array}{ll}\text { Marketing de } \\
\text { Relacionamento }\end{array}$ & $\begin{array}{l}\text { Ineditismo } \\
\text { no Brasil }\end{array}$ & Abertura da Inovação & $\begin{array}{l}\text { Novas Tecnologias / } \\
\text { Método }\end{array}$ & Benefícios & Implicações \\
\hline $\begin{array}{l}\text { Identificação } \\
\text { do perfil dos } \\
\text { alunos da IES. }\end{array}$ & $\begin{array}{l}\text { Direção e } \\
\text { Marketing. }\end{array}$ & $\begin{array}{l}\text { Melhoria no } \\
\text { relacionamento com o } \\
\text { aluno, oferecendo } \\
\text { serviços segmentados } \\
\text { para o público atendido } \\
\text { pela IES. }\end{array}$ & $\begin{array}{l}\text { Existe em } \\
\text { outras IES no } \\
\text { Brasil. }\end{array}$ & $\begin{array}{l}\text { Inovação aberta: participação } \\
\text { de outra IES do grupo na } \\
\text { transferência do instrumento } \\
\text { de pesquisa. }\end{array}$ & $\begin{array}{l}\text { Novo instrumento de } \\
\text { pesquisa e novo } \\
\text { método de aplicação, } \\
\text { com o auxilio de } \\
\text { software para o } \\
\text { tratamento de dados. }\end{array}$ & $\begin{array}{l}\text { Otimização dos } \\
\text { recursos, } \\
\text { aplicando-os de } \\
\text { forma assertiva. }\end{array}$ & $\begin{array}{l}\text { Falta de } \\
\text { disposição dos } \\
\text { alunos para } \\
\text { responder as } \\
\text { pesquisas. }\end{array}$ \\
\hline $\begin{array}{l}\text { Divulgação da } \\
\text { IES com a } \\
\text { utilização do } \\
\text { Google } \\
\text { adwors. }\end{array}$ & $\begin{array}{l}\text { Marketing } \\
\text { e } \\
\text { Tecnologia } \\
\text { da } \\
\text { Informação. }\end{array}$ & $\begin{array}{l}\text { Aumento do raio de } \\
\text { atuação da IES, atingindo } \\
\text { mais pessoas interessadas } \\
\text { em graduação. Acesso aos } \\
\text { prospects que não eram } \\
\text { atendidos. }\end{array}$ & $\begin{array}{l}\text { Existe em } \\
\text { outras IES no } \\
\text { Brasil. }\end{array}$ & $\begin{array}{l}\text { Inovação aberta apenas para os } \\
\text { ajustes de Software } \\
\text { gerenciador do método. }\end{array}$ & Novo software. & $\begin{array}{l}\text { Aumento da } \\
\text { procura pelos } \\
\text { cursos } \\
\text { oferecidos pela } \\
\text { IES, em relação } \\
\text { aos vestibulares } \\
\text { anteriores. } \\
\end{array}$ & $\begin{array}{l}\text { Não } \\
\text { apresentou } \\
\text { dificuldades. }\end{array}$ \\
\hline $\begin{array}{l}\text { Comunicação } \\
\text { com os alunos } \\
\text { e comunidade } \\
\text { através das } \\
\text { Redes Sociais. }\end{array}$ & Marketing. & $\begin{array}{l}\text { Maior contato com os } \\
\text { alunos e comunidade. }\end{array}$ & $\begin{array}{l}\text { Existe em } \\
\text { outras IES no } \\
\text { Brasil. }\end{array}$ & $\begin{array}{l}\text { Inovação fechada. Método } \\
\text { desenvolvido pela equipe de } \\
\text { Tecnologia da Informação. } \\
\text { Software adquirido } \\
\text { externamente, mas ajustado } \\
\text { internamente. }\end{array}$ & $\begin{array}{l}\text { Novo software, } \\
\text { desenvolvendo um } \\
\text { novo portal de } \\
\text { interação com os } \\
\text { alunos. }\end{array}$ & $\begin{array}{l}\text { Maior } \\
\text { velocidade de } \\
\text { respostas aos } \\
\text { alunos e } \\
\text { facilidade dos } \\
\text { alunos } \\
\text { acessarem as } \\
\text { informações da } \\
\text { faculdade. }\end{array}$ & $\begin{array}{l}\text { Dificuldades } \\
\text { iniciais de } \\
\text { adaptação ao } \\
\text { novo software } \\
\text { e aos novos } \\
\text { meios de } \\
\text { comunicação. }\end{array}$ \\
\hline $\begin{array}{l}\text { Estruturação } \\
\text { do setor de } \\
\text { Marketing e } \\
\text { Vendas. }\end{array}$ & $\begin{array}{l}\text { Direção, } \\
\text { Marketing } \\
\text { e Vendas. }\end{array}$ & $\begin{array}{l}\text { Melhoria do atendimento } \\
\text { presencial e virtual às } \\
\text { demandas dos alunos. } \\
\text { Campanhas } \\
\text { desenvolvidas com maior } \\
\text { acertividade em relação } \\
\text { ao perfil do aluno. }\end{array}$ & $\begin{array}{l}\text { Existe em } \\
\text { outras IES no } \\
\text { Brasil. }\end{array}$ & $\begin{array}{l}\text { Inovação fechada. Método } \\
\text { desenvolvido pela Direção e } \\
\text { Coordenação de Marketing. }\end{array}$ & $\begin{array}{l}\text { Novo método de } \\
\text { gestão do marketing } \\
\text { da IES e novo } \\
\text { software para gerar } \\
\text { as informações. }\end{array}$ & $\begin{array}{l}\text { Otimização dos } \\
\text { recursos } \\
\text { materiais e } \\
\text { humanos. }\end{array}$ & $\begin{array}{l}\text { Dificuldades } \\
\text { iniciais de } \\
\text { adaptação as } \\
\text { novas funções. }\end{array}$ \\
\hline $\begin{array}{l}\text { Mudança no } \\
\text { logotipo } \\
\text { utilizado para }\end{array}$ & $\begin{array}{l}\text { Direção e } \\
\text { Marketing. }\end{array}$ & $\begin{array}{l}\text { Alunos se identificam } \\
\text { com a nova marca da IES. }\end{array}$ & $\begin{array}{l}\text { Existe em } \\
\text { outras IES no } \\
\text { Brasil. }\end{array}$ & $\begin{array}{l}\text { Inovação fechada } \\
\text { desenvolvida pelos setores de } \\
\text { ensino e registro acadêmico. } \mathrm{O}\end{array}$ & $\begin{array}{l}\text { Sem adoção de novo } \\
\text { de software ou } \\
\text { método. }\end{array}$ & $\begin{array}{l}\text { A marca está } \\
\text { mais alinhada ao } \\
\text { novo }\end{array}$ & $\begin{array}{l}\text { Não } \\
\text { apresentou } \\
\text { dificuldades. }\end{array}$ \\
\hline
\end{tabular}




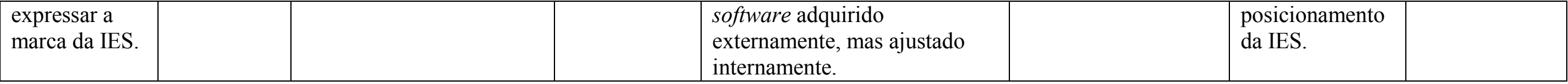

Quadro 3 Inovações em marketing da IES F2

Fonte: Dados provenientes da pesquisa (2011).

\begin{tabular}{|c|c|c|c|c|c|c|c|}
\hline Inovações & $\begin{array}{l}\text { Setores } \\
\text { Envolvidos }\end{array}$ & $\begin{array}{l}\text { Marketing de } \\
\text { Relacionamento }\end{array}$ & $\begin{array}{l}\text { Ineditismo } \\
\text { no Brasil }\end{array}$ & $\begin{array}{l}\text { Abertura da } \\
\text { Inovação }\end{array}$ & $\begin{array}{l}\text { Novas Tecnologias / } \\
\text { Método }\end{array}$ & Benefícios & Implicações \\
\hline $\begin{array}{l}\text { Mudança da forma } \\
\text { de apresentar a } \\
\text { IES, através de um } \\
\text { vídeo Institucional } \\
\text { que demonstra as } \\
\text { áreas de atuação } \\
\text { dos cursos. }\end{array}$ & $\begin{array}{l}\text { Ensino, } \\
\text { Marketing e } \\
\text { Comunicação. }\end{array}$ & $\begin{array}{l}\text { Desperta o } \\
\text { interesse dos } \\
\text { futuros alunos, pois } \\
\text { são empresários } \\
\text { falando sobre o } \\
\text { perfil e a demanda } \\
\text { de profissionais da } \\
\text { área. }\end{array}$ & $\begin{array}{l}\text { Não foi } \\
\text { identificada } \\
\text { em outras } \\
\text { IES no } \\
\text { Brasil. }\end{array}$ & $\begin{array}{l}\text { Inovação Aberta } \\
\text { com envolvimento } \\
\text { de agência de } \\
\text { publicidade externo } \\
\text { e setores internos } \\
\text { de Ensino, } \\
\text { Marketing e } \\
\text { Comunicação. }\end{array}$ & $\begin{array}{l}\text { Novo conceito de } \\
\text { comunicação. }\end{array}$ & $\begin{array}{l}\text { Melhoria na forma } \\
\text { de comunicar os } \\
\text { benefícios de uma } \\
\text { graduação, } \\
\text { aumentando a } \\
\text { percepção de valor } \\
\text { dos cursos } \\
\text { oferecidos pela } \\
\text { IES. }\end{array}$ & $\begin{array}{l}\text { Dificuldades iniciais } \\
\text { para obter apoio de } \\
\text { empresários e } \\
\text { representantes de } \\
\text { empresas para } \\
\text { participar do vídeo, } \\
\text { que após entendido o } \\
\text { conceito esta foi } \\
\text { superada. }\end{array}$ \\
\hline $\begin{array}{l}\text { Comunicação e } \\
\text { interação com os } \\
\text { alunos através das } \\
\text { Redes Sociais. }\end{array}$ & $\begin{array}{l}\text { Ensino, } \\
\text { Marketing e } \\
\text { Comunicação. }\end{array}$ & $\begin{array}{l}\text { Melhora a interação } \\
\text { com os alunos e } \\
\text { aumenta o raio de } \\
\text { atuação da IES, } \\
\text { atingindo mais } \\
\text { pessoas } \\
\text { interessadas em } \\
\text { graduação. }\end{array}$ & $\begin{array}{l}\text { Existe em } \\
\text { outras IES no } \\
\text { Brasil. }\end{array}$ & $\begin{array}{l}\text { Inovação Aberta } \\
\text { com envolvimento } \\
\text { de agência de } \\
\text { publicidade externo } \\
\text { e setores internos } \\
\text { de Ensino, } \\
\text { Marketing e } \\
\text { Comunicação. }\end{array}$ & $\begin{array}{l}\text { Novo método de } \\
\text { rematrículas e novo } \\
\text { software. }\end{array}$ & $\begin{array}{l}\text { Ampliação dos } \\
\text { meios que } \\
\text { viabilizam a } \\
\text { comunicação entre } \\
\text { aluno e a IES. } \\
\text { Aproximação do } \\
\text { aluno com os } \\
\text { professores, } \\
\text { coordenadores e } \\
\text { serviços } \\
\text { administrativos. }\end{array}$ & $\begin{array}{l}\text { Poucas dificuldades } \\
\text { para a equipe } \\
\text { entender a linguagem } \\
\text { e utilizar as redes. }\end{array}$ \\
\hline $\begin{array}{l}\text { Mudança no } \\
\text { conceito da } \\
\text { Campanha de } \\
\text { Vestibular, focando }\end{array}$ & $\begin{array}{l}\text { Ensino, } \\
\text { Marketing e } \\
\text { Comunicação. }\end{array}$ & $\begin{array}{l}\text { Demonstra o valor } \\
\text { que a IES agrega à } \\
\text { formação } \\
\text { profissional. }\end{array}$ & $\begin{array}{l}\text { Existe em } \\
\text { outras IES no } \\
\text { Brasil. }\end{array}$ & $\begin{array}{l}\text { Inovação Aberta } \\
\text { com envolvimento } \\
\text { de agência de } \\
\text { publicidade externo }\end{array}$ & $\begin{array}{l}\text { Novo método de } \\
\text { analise e novo } \\
\text { software. }\end{array}$ & $\begin{array}{l}\text { O discurso direto } \\
\text { facilitou o } \\
\text { entendimento dos } \\
\text { alunos sobre os } \\
\end{array}$ & $\begin{array}{l}\text { Não apresentou } \\
\text { dificuldades. }\end{array}$ \\
\hline
\end{tabular}


INOVAÇÃO DE MARKETING EM INSTITUIÇÕES DE ENSINO SUPERIOR DA SERRA GAÚCHA

DOI: http://dx.doi.org/10.5007/1983-4535.2013v6n2p79

\begin{tabular}{|c|c|c|c|c|c|c|c|}
\hline $\begin{array}{l}\text { na qualificação do } \\
\text { profissional } \\
\text { oriundo da IES. }\end{array}$ & & $\begin{array}{l}\text { Contribui para o } \\
\text { aumento da } \\
\text { confiança na IES. }\end{array}$ & & $\begin{array}{l}\text { e setores internos } \\
\text { de Ensino, } \\
\text { Marketing e } \\
\text { Comunicação. }\end{array}$ & & $\begin{array}{l}\text { benefícios dos } \\
\text { cursos. }\end{array}$ & \\
\hline $\begin{array}{l}\text { Estruturação de um } \\
\text { núcleo de apoio ao } \\
\text { estudante. }\end{array}$ & $\begin{array}{l}\text { Ensino e } \\
\text { Marketing. }\end{array}$ & $\begin{array}{l}\text { Aumenta as } \\
\text { possibilidades de } \\
\text { identificação das } \\
\text { necessidades dos } \\
\text { alunos e oferece } \\
\text { soluções mais } \\
\text { assertivas. }\end{array}$ & $\begin{array}{l}\text { Existe em } \\
\text { outras IES no } \\
\text { Brasil. }\end{array}$ & $\begin{array}{l}\text { Inovação Fechada, } \\
\text { desenvolvida pela } \\
\text { área de Ensino. }\end{array}$ & $\begin{array}{l}\text { Novo método de } \\
\text { inscrições e } \\
\text { certificas. Novo } \\
\text { software. }\end{array}$ & $\begin{array}{l}\text { Maior contato com } \\
\text { os alunos. Aumento } \\
\text { da acertividade nos } \\
\text { cursos oferecidos } \\
\text { para os alunos. } \\
\text { Rapidez na solução } \\
\text { dos problemas } \\
\text { levantados. }\end{array}$ & $\begin{array}{l}\text { Poucas dificuldades } \\
\text { para os alunos } \\
\text { operarem o software. }\end{array}$ \\
\hline $\begin{array}{l}\text { Programa de } \\
\text { atração e retenção } \\
\text { de alunos. }\end{array}$ & $\begin{array}{l}\text { Ensino e } \\
\text { Marketing. }\end{array}$ & $\begin{array}{l}\text { Identifica o perfil } \\
\text { de possíveis alunos, } \\
\text { oferecendo-lhes } \\
\text { solução de } \\
\text { formação } \\
\text { profissional. } \\
\text { Através de } \\
\text { entrevistas } \\
\text { identifica os } \\
\text { motivos de saídas } \\
\text { dos alunos e busca } \\
\text { resolvê-los. }\end{array}$ & $\begin{array}{l}\text { Existe em } \\
\text { outras IES no } \\
\text { Brasil. }\end{array}$ & $\begin{array}{l}\text { Inovação Fechada, } \\
\text { desenvolvida pela } \\
\text { área de Marketing e } \\
\text { Ensino. }\end{array}$ & $\begin{array}{l}\text { Novo método de } \\
\text { pesquisa e } \\
\text { atendimento ao } \\
\text { aluno. Uso de } \\
\text { software para } \\
\text { suporte. }\end{array}$ & $\begin{array}{l}\text { Melhoria da } \\
\text { qualidade do } \\
\text { ensino. Mais } \\
\text { práticas } \\
\text { profissionais. } \\
\text { Aumento da } \\
\text { procura de novos } \\
\text { alunos. Redução no } \\
\text { percentual de } \\
\text { evasão. }\end{array}$ & $\begin{array}{l}\text { Inicialmente } \\
\text { demandou muita } \\
\text { energia em } \\
\text { planejamento para } \\
\text { ajustar os processos } \\
\text { internos e definir } \\
\text { responsabilida-des. }\end{array}$ \\
\hline
\end{tabular}

Quadro 4 Inovações em marketing da IES F3

Fonte: Dados provenientes da pesquisa (2011). 


\begin{tabular}{|c|c|c|c|c|c|c|}
\hline IES & Foco das Inovações e Setores Envolvidos & $\begin{array}{ll}\text { Ineditismo e Abertura das } \\
\text { Inovações }\end{array}$ & $\begin{array}{l}\text { Marketing de } \\
\text { Relacionamento }\end{array}$ & $\begin{array}{l}\text { Novas } \\
\text { Tecnologias }\end{array}$ & Benefícios & Implicações \\
\hline F1 & $\begin{array}{l}\text { Divulgação dos cursos e flexibilização das } \\
\text { aulas, evolvendo os setores de Marketing e } \\
\text { Ensino. }\end{array}$ & $\begin{array}{l}\text { Inovações já conhecidas pelo } \\
\text { mercado nacional. } \\
\text { Inovação fechada. }\end{array}$ & $\begin{array}{l}\text { Melhoria na } \\
\text { relação com os } \\
\text { fornecedores e com } \\
\text { os alunos. }\end{array}$ & $\begin{array}{l}\text { Novo } \\
\text { software para } \\
\text { atender às } \\
\text { inovações. }\end{array}$ & $\begin{array}{l}\text { Melhoria em } \\
\text { comunicação e } \\
\text { satisfação dos } \\
\text { alunos. }\end{array}$ & $\begin{array}{l}\text { Aumentos dos } \\
\text { custos e } \\
\text { resistência inicial. }\end{array}$ \\
\hline F2 & $\begin{array}{l}\text { Pesquisas de perfil dos alunos, comunicação e } \\
\text { estrutura da organização, envolvendo os } \\
\text { setores de Direção e Marketing. }\end{array}$ & $\begin{array}{l}\text { Inovações já conhecidas pelo } \\
\text { mercado nacional. } \\
\text { Inovação fechada. }\end{array}$ & $\begin{array}{l}\text { Melhoria na } \\
\text { relação com os } \\
\text { alunos. }\end{array}$ & $\begin{array}{l}\text { Novo } \\
\text { software para } \\
\text { atender às } \\
\text { inovações. }\end{array}$ & $\begin{array}{l}\text { Melhoria em } \\
\text { comunicação, } \\
\text { rapidez na } \\
\text { resposta às } \\
\text { demandas dos } \\
\text { alunos, } \\
\text { aumento de } \\
\text { novos alunos, } \\
\text { melhor uso } \\
\text { dos recursos. }\end{array}$ & $\begin{array}{l}\text { Poucas } \\
\text { dificuldades } \\
\text { iniciais de } \\
\text { adaptação das } \\
\text { pessoas ao novo } \\
\text { método e ou } \\
\text { software. }\end{array}$ \\
\hline F3 & $\begin{array}{l}\text { Divulgação da IES , comunicação e } \\
\text { atendimento ás demandas dos alunos, } \\
\text { envolvendo os setores de Marketing e Ensino. }\end{array}$ & $\begin{array}{l}\text { Apenas uma inovação } \\
\text { considerada inédita no Brasil. } \\
\text { Três Inovações abertas. }\end{array}$ & $\begin{array}{l}\text { Melhoria na } \\
\text { relação com os } \\
\text { alunos. }\end{array}$ & $\begin{array}{l}\text { Novo } \\
\text { software para } \\
\text { atender às } \\
\text { inovações e } \\
\text { novos } \\
\text { métodos. }\end{array}$ & $\begin{array}{l}\text { Melhoria da } \\
\text { qualidade de } \\
\text { ensino e } \\
\text { comunicação } \\
\text { com os alunos. } \\
\text { Aumento de } \\
\text { novos alunos. }\end{array}$ & $\begin{array}{l}\text { Poucas } \\
\text { dificuldades } \\
\text { iniciais de } \\
\text { adaptação das } \\
\text { pessoas ao novo } \\
\text { método e ou } \\
\text { software. }\end{array}$ \\
\hline
\end{tabular}

Quadro 5 Resumo das inovações em marketing nas IES pesquisadas

Fonte: Dados provenientes da pesquisa (2011). 


\section{REFERÊNCIAS}

AFONSO, C. W. Master in bussiness administration (MBA) versus Mestrado profissionalizante em administração (MPA): Diferenças e similaridades. Rio de Janeiro: EBAP FGV, 2005.

ABERNATHY, W. J.; CLARK, K. B. Innovation: mapping the winds of creative destruction. Research Policy, v.14, n. 1, p.3-22, Feb. 1985.

ANSOFF, I. Strategies for diversification. Harvard Business Review, v. 35, n. 5, p. 113-124, Set/Out. 1957.

BARDIN, L. Análise de conteúdo. 3 ed. Lisboa: Edições 70, 2004.

BENNETT, R. C.; COOPER, R. G. Beyond the marketing concept. Business Horizons, v. 22, n. 3, p. 76-83, 1979.

BENNETT, R. C.; COOPER, R. G. The misuse of marketing: An American tragedy.

Business Horizons, v. 24, n. 6, p. 51-61, 1981.

BESSANT, J., LAMMING, R., NOKE, H., PHILLIP, W. Managing innovation beyond the steady state. Technovation, v. 25, n. 12, p. 1366-1376, Oct. 2005.

BROWN, S. L., EISENHARDT, K. M. Product development: past research, present findings, and future directions. Academy of Management Review, v. 20, n. 2, p. 343-378, Apr. 1995.

CARBONELL, J. A aventura de inovar: a mudança na escola. Porto Alegre: Artmed, 2002.

CARVALHO, H. G. Tecnologia, inovação e educação: chaves para a competitividade. Porto Alegre: Artmed, 1998.

COOPER, J. R. A multidimensional approach to the adoption of innovation. Management Decision, v. 36, n. 8, p. 493-502, 1996.

DAMANPOUR, F. Organizational innovation: a meta-analysis of effects of determinants and moderators. Academy of Management Journal, v. 34, n. 3, p. 555-590, 1991.

DRUCKER, P. F. As fronteiras da administração. São Paulo: Pioneira, 1989.

DRUCKER, P. The discipline of innovation. Harvard Business Review. New York: Harvard Business School Press, p. 80-85, Aug. 2002.

FLICK, U. Uma introdução à pesquisa qualitativa. Porto Alegre: Bookman, 2004.

FEE - FUNDAÇÃO DE ECONOMIA E ESTATÍSTICA. Disponível em: $<$ http://www.fee.tche.br/sitefee/pt/content/resumo/pg_coredes_detalhe.php? corede=Serra $>$ Acesso em: nov. 2011. 
FREEMAN, C; SOETE, L. The economics of industrial innovation. 3 ed. Cambridge: MIT Press, 1997.

GALlOUJ, F.; WEINSTEIN, O. Innovation in services. Research Policy, v. 26, n. 4/5, p. 537-556, Dec. 1997.

GIBBS, G. Análise de Dados Qualitativos. Porto Alegre: Bookman, 2009.

GRÖNROOS, C. Relationship marketing: the Nordic school perspective. In: SHETH, J. N.; PARCATIYAR, A. (eds). Handbook of relationship marketing. Thousand Oaks: Sage Publications, cap. 4, p. 95-117, 2000.

GRÖNROOS, C. Relationship Marketing: Strategic and Tactical Implications. Marketing Management Decision, v. 34, n. 3, p. 5-14, 1996.

GRÖNROOS, C. Marketing: gerenciamento e serviços. 2. ed. Rio de Janeiro: Elsevier, 2004.

HAIR Jr., J. F.; BUSH, R. P.; ORTINAU, D. J. Marketing research: a practical approach for the new millennium. New York: Irwin/McGraw-Hill, 2000.

HERNÁNDEZ. F.; SANCHO, J. M.; CARBONELL, J.; TORT, A.; SIMÓ, N.; CORTÉS, E. S. Aprendendo com inovação nas escolas. Porto Alegre: Arte Médicas Sul, 2000.

HIGGINS, J. M. Innovate or evaporate: Test \& Improve Your Organization's IQ - It's Innovation Quotient. New York: New Management Publishing, 1995.

INEP. SINAES: Da concepção à regulamentação. Brasilia: Editora INEP/MEC, 2004.

INEP. Resumo Técnico do Censo da Educação Superior 2009. Disponível em: $<$ http://portal.inep.gov.br/web/censo-da-educacao-superior/resumos-tecnicos $>$. Acesso em: 21 dez. 2011.

JOHNE, A., DAVIES, R. Innovation in medium-sized insurance companies: how marketing adds value. International Journal of Bank Marketing, v. 18 n. 1, p. 6-14, 2000.

KALSBEK, D. H. Marketing e Gerenciamento de matrículas na educação superior. In: KOTLER, P. Administração de Marketing: a edição do novo milênio. 10. ed. São Paulo: Prentice Hall, 2000.

KOTLER, P.; KELLER, K. L. Administração de marketing. 12. ed. São Paulo: Prentice Hall, 2006.

MACADAR, B. M. Pode o marketing de relacionamento gerar vantagem competitiva? In: SLONGO, L. A.; LIBERALI, G. (org.). Marketing de relacionamentos: estudos, cases e proposições de pesquisa. São Paulo: Atlas, 2004.

MANUAL DE OSLO - The measurement of scientific and technological activities. 2005. 
MALHOTRA, N. K. Pesquisa de marketing: uma orientação aplicada. 4 ed. São Paulo: Bookman, 2006.

MEC - MINISTÉRIO DA EDUCAÇÃO DO BRASIL. Disponível em:

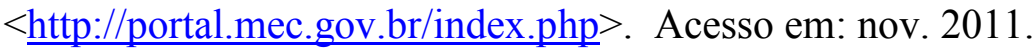

MICHAEL, S. O. In search of universal principles of higher education management andapplicability to Moldavian higher education system. The International Journal of Educational Management, v. 18, n. 2, p. 118-137, 2004.

MILAN, G. S. A retenção de clientes como resultado da prática do marketing de relacionamento. In: MILAN, G. S.; BRANCHI, N. V. L. (org.) Administração mercadológica: teoria e pesquisas. Volume 1. Caxias do Sul: EDUCS, 2004.

MÖLLER, K.; HALINEN, A. Relationship Marketing Theory: Its Roots and Direction. Journal of Marketing Management, v. 16, n. 1/3, p. 29-54, 2000.

MORGAN, R. M.; HUNT, S. D. The commitment-trust theory of relationship marketing. Journal of marketing, v. 58, n. 3, p. 20-38, July 1994.

NAIDOO, V. Firm survival through a crisis: The influence of market orientation, marketing innovation and business strategy. Industrial Marketing Management, v. 39, n. 8, p. 13111320, Nov. 2010.

NÓVOA, A. As organizações escolares em análise. 2. ed. Lisboa: Publicações Dom Quixote, 1995.

NUNES, G. T. Abordagem do marketing de relacionamento no ensino superior. Gestão e Regionalidade, v. 24, n. 69, jan-abr 2008.

NUNES, M. C. Inovação Estratégica nas Instituições de Ensino Superior no Brasil. Dissertação (Mestrado em Gestão de Empresas), Instituto Universitário de Lisboa, 2009.

OECD. Proposed guidelines for colleting and interpreting innovation data: Oslo Manual, third edition. Paris: OECD, 2005.

PALACIO, A. B.; MENESES, G. D.; PÉREZ, P. J. P. The configuration of the university image and its relationship with the satisfaction of students. Journal of Educational Administration, v. 40, n. 5, p. 486-505, 2002.

PALMATIER, R. W.; DANT, R. P.; EVANS, K. R. Factors influencing the effectiveness of relationship marketing: a meta-analysis. Journal of Marketing, v. 70, n. 4, p. 136-53, Jul. 2006.

PARVATIYAR, A.; SHETH J. N. The domain and conceptual foundations os relationship marketing. In: SHETH, J. N.; PARVATIYAR, A (eds). Handbok of relationship marketing. Thousand Oaks: Sage Publications, cap 1, p. 3-38, 2000. 
PINTEC - PESQUISA DE INOVAÇÃO TECNOLÓGICA. Rio de Janeiro: IBGE, 2010.

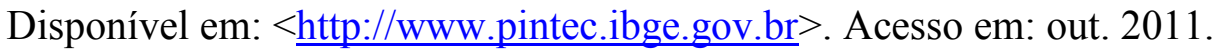

PORTER, M. E. Estratégia: a busca da vantagem competitiva. 6 ed. Rio de Janeiro: Campus, 2001.

SARKAR, S. O empreendedor inovador. Rio de Janeiro: Elsevier, 2008.

SEVERO, E. A.; GUIMARÃES, J. C. F. de; DORION, E.; ESTIVALET, E. L. Inovação em Serviços Educacionais: Estudo de Caso em Uma Instituição de Ensino Superior na Serra Gaúcha. VII CNEG - Congresso Nacional de Excelência em Gestão, Rio de Janeiro, 2011.

SILVA, G. J. C. O ensino superior privado: O conflito entre lucro, expansão e qualidade. Tese (Doutorado em Sociologia), Universidade de Brasília, 2008.

SCHUMPETER, J. A. The Theory of Economic Development. Cambridge: Harvard University Press, 1934.

SCHUMPETER, J. A. Capitalism Socialism and Democracy. 3 ed. New York: Harper and Row, 1950.

TARRY, S. E. Innovation in the Administration of Public Airports. Arlington: Grant Report, The PricewaterhouseCoopers Endowment for the Business of Government, March 2000.

TIDD, J.; BESSANT. J.; PAVITT. K. Managing innovation. Integrating technological, market and organizational change. 3. ed. The Atrium, Southern. Gate, Chichester, England: John Wiley \& Sons Ltd, 2005.

Vergara, S.C. Projetos e relatórios de pesquisa em administração. 7 ed. São Paulo: Atlas, 2006.

YIN, R. K. Case study research: design and methods. 4. ed. v. 5. Thousand Oaks, CA: Sage Publication, 2009. 